\section{Host Resistance and Metam Sodium for Managing Root-knot Nematodes in a Pepper-Cucumber Rotation}

Judy A. Thies ${ }^{1}$

U.S. Department of Agriculture, Agricultural Research Service, U.S. Vegetable Laboratory, Charleston, SC 29414

Richard F. Davis ${ }^{2}$

U.S. Department of Agriculture, Agricultural Research Service, Crop Protection and Management Research Unit, Tifton, GA 31793

John D. Mueller ${ }^{3}$

Clemson University, Edisto Research and Education Center, Blackville, SC 29817

Richard L. Fery ${ }^{4}$

U.S. Department of Agriculture, Agricultural Research Service, U.S. Vegetable Laboratory, Charleston, SC29414

David B. Langston ${ }^{5}$

Rural Development Center, University of Georgia, Tifton, GA 31793

Gilbert Miller 6

Clemson University, Edisto Research and Education Center, Blackville, SC 29817

Additional index words. Capsicum annuum var. annuum, Cucumis sativus, Meloidogyne

incognita, metam sodium, nematode resistance, root-knot nematode

Abstract. Root-knot nematode-resistant 'Charleston Belle'bell pepper (Capsicum annuum L. var. annuиm) and metam sodium treatment were evaluated for managing the southern root-knot nematode [Meloidogyne incognita (Chitwood) Kofoid and White] in fall-cropped cucumber (Cucumis sativus L.). 'Charleston Belle' and its susceptible recurrent parent, 'Keystone Resistant Giant', were planted as spring crops at Blackville, S.C., and Tifton, Ga. 'Charleston Belle' exhibited high resistance and 'Keystone Resistant Giant' was susceptible at both locations. After termination of the bell pepper crop, one-half of the plots were treated with metam sodium delivered through the drip irrigation system. Cucumber yields and numbers of fruit were highest for cucumber grown in plots treated with metam sodium following either 'Charleston Belle' or 'Keystone Resistant Giant'; however, root gall severity and numbers of $M$. incognita eggs in the roots were lowest for cucumber grown in plots treated with metam sodium following 'Charleston Belle'. Conversely, root gall severity and nematode reproduction were highest for cucumber grown in plots following 'Keystone Resistant Giant' without metam sodium treatment. Application of metam sodium through the drip irrigation system following a spring crop of root-knot nematode-resistant bell pepper should reduce severity of root galling and reproduction of $M$. incognita as well as increase fruit yield of fall-cropped cucumber.

The southern root-knotnematode, Meloidogyne incognita (Chitwood) Kofoid and White, greatly reduces pepper and cucumber yields in the U.S. (Colyer et al., 1998; Thies et al., 1998; Webster et al., 2001). Preplant soil fumigation with methyl bromide is the primary method for controlling root-knot nematodes in bell pepper and cucumber (USDA, 1998). However, production and use of methyl bro-

Received for publication 6 June 2005. Accepted for publication 13 July 2005. The authors thank S.B. Merrill, P. Berland, T. Hilton, and A.K. Montfort for technical assistance in conducting the experiments.

${ }^{1}$ Research plant pathologist. Corresponding author; e-mail jthies@saa.ars.usda.gov.

${ }^{2}$ Research plant pathologist.

${ }^{3}$ Professor

${ }^{4}$ Research geneticist.

${ }^{5}$ Associate professor.

${ }^{6}$ Senior county extension agent. sistant tomato produced higher yields, and had reduced root galling and lower densities of $M$. incognita second-stage juveniles (J2) in the soil than cucumber grown after susceptible tomato (Colyer et al., 1998; Hanna et al., 1994).

The root-knotnematode-resistant ' Charleston Belle' bell pepper was developed and released by USDA-ARS scientists in Charleston, S.C. (Fery et al., 1998). Root-knot nematode resistance in 'Charleston Belle' is conditioned by the single dominant $N$ gene. In Georgia, 'Charleston Belle' and the susceptible bell pepper 'Camelot' were planted as a spring crop in rotation with a fall crop of 'Dixie' yellow squash (Webster et al., 2001). Soil densities of $M$. incognita J2 observed in 'Charleston Belle' plots were about $11 \%$ of those observed in 'Camelot' plots. Studies in South Carolina and Georgia demonstrated that 'Charleston Belle' reduced root galling and increased fruit yields of cucumber grown as a fall crop after 'Charleston Belle' compared with cucumber grown after the susceptible 'Keystone Resistant Giant' bell pepper (Thies et al., 2004). Thies et al. (2004) suggested that although rootknot nematode resistant bell pepper reduced root-knot nematode damage and increased fruit yields in the subsequent cucumber crop, application of a fumigant nematicide after the resistant pepper spring crop may further reduce root-knot nematode damage and increase yield in the fall cucumber crop. The objective of these studies was to determine the potential of using a resistant bell pepper cultivar in combination with metam sodium for managing $M$. incognita in double-cropped cucumber in South Carolina and Georgia.

\section{Materials and Methods}

Field studies were conducted at the Clemson University Edisto Research and Education Center, Blackville, S.C., and the USDA-ARS Crop Protection and Management Research Unit, Tifton, Ga. A spring bell pepper crop and a fall cucumber crop were planted on the same plots at both field sites. One-half of the plots were treated with metam sodium applied through the drip system at termination of the pepper crop. A pair of near-isogenic pepper cultivars that differ for resistance to root-knot nematode conditioned by the $N$ gene was used in these studies. The bell pepper cultivars were 'Charleston Belle' (NN) and 'Keystone Resistant Giant' $(n n)$ and the cucumber cultivar was 'Stonewall'.

Egg inocula. Meloidogyne incognita race 3 egg inocula was maintained on tomato (Lycopersicon esculentum Mill. 'Rutgers') in separate greenhouse benches. Egg inocula of $M$. incognita were extracted from infected tomato and bean (Phaseolus vulgaris L.) roots using $0.5 \% \mathrm{NaOCl}$ (Hussey and Barker, 1973).

Blackville bell pepper-cucumber rotation. Pepper seeds were planted in the greenhouse on 13 Mar. 2003. On 8 Apr. 2003, the pepper seedlings were inoculated with about 3,000 $M$. incognita race 3 eggs per seedling. On 22 Apr. 2003, the beds were prepared and covered with 3-mL black plastic. On 23 Apr. 2003, eight cores of soil $20 \mathrm{~cm}$ deep were collected 
from each plot and combined into a single sample for nematode extractions. On the same day, pepper seedlings were transplanted into single-row plots on beds $2 \mathrm{~m}$ apart. Each plot contained 25 plants spaced $30-\mathrm{cm}$ apart. The experimental design was a randomized complete block with two pepper cultivars $\times$ two metam sodium treatments (an untreated control and $467 \mathrm{~L} \cdot \mathrm{ha}^{-1}$ ) and ten replications. Secondstage juveniles (J2) were extracted from 113 $\mathrm{cm}^{3}$ soil from each sample using the centrifugal flotation method (Jenkins, 1964).

Standard cultural and insect control practices were followed and plots were irrigated with a subsurface drip system (N.C. Vegetable Growers Association, 2004). Soil temperatures were recorded at 60-minute intervals at 5- and $15-\mathrm{cm}$ depths in the row from 6 May through 10 Nov. 2003. Fruit were harvested from 10 plants in the center of each plot on 18 June, 2 July, 10 July, and 16 July 2003. On 16 July 2003 , eight pepper root systems with the surrounding rhizosphere soil were dug from each plot. The roots were washed and rated for gall severity using a scale of 1 to 5 , where $1=0$ to $3 \%$ root system galled or covered with egg masses; $2=4 \%$ to $25 \%, 3=26 \%$ to $50 \%, 4=$ $51 \%$ to $79 \%$, and $5=\geq 80 \%$ root system galled (Thies et al., 1998). Meloidogyne incognita eggs were extracted from a 20 -g subsample of roots from each plot using $1 \% \mathrm{NaOCl}$ (Hussey and Barker, 1973). Second-stage juveniles were extracted from $113 \mathrm{~cm}^{3}$ rhizosphere soil as previously described. On 14 Aug. 2003, one-half of the plots were treated with metam sodium at $467 \mathrm{~L} \cdot \mathrm{ha}^{-1}$ applied through the drip irrigation system. The black plastic was sprayed with whitewash.

On 4 Sept. 2003, two seeds of 'Stonewall' cucumber were sown in the hole where each bell pepper plant had previously grown. Cucumber seedlings were thinned to one per hill after emergence. Standard cultural and pest control practices were followed and plots were subsurface drip irrigated. Five cucumber plants were dug from the center of each plot on 9 Oct. 2003. The shoots were cut at the base of each plant and weights were recorded. The roots were washed and rated for gall severity and egg mass production using a scale of 1 to 5 , as previously described. Meloidogyne incognita eggs were extracted from the roots using $1 \% \mathrm{NaOCl}$ (Hussey and Barker, 1973). Fruit were harvested from five plants in each plot on 6 Nov. 2003.

Tifton bell pepper-cucumber rotation. Field preparation, pest control and cultural practices, and experimental design were as described for the Blackville study. Pepper seedlings were transplanted to the field on 7 May 2003. Soil samples were collected on 16 May 2003 and $M$. incognita $\mathrm{J} 2$ were extracted as previously described. Pepper fruit were harvested from all plants in each plot on 8 and 22 July 2003. The root systems of six pepper plants were dug from the center of each plot on 23 July 2003. The roots were rated for gall severity and eggs were extracted from $20 \mathrm{~g}$ of fibrous roots as previously described. On 28 July 2003, one-half the plots were treated with metam sodium at $467 \mathrm{~L} \cdot \mathrm{ha}^{-1}$ applied through the drip irrigation system. The black plastic was sprayed with whitewash.

Seeds of 'Stonewall' cucumber were sown on 12 Aug. 2003. Fruit were harvested from all plants in each plot on 14 Oct., 17 Oct., and 20 Oct. 2003. On 27 Oct. 2003, the root systems of all cucumber plants were dug and rated for gall severity. Meloidogyne incognita eggs were extracted from the root samples as previously described.

Data analysis. Nematode egg and J2 data were $\log _{10}(\mathrm{x}+1)$ transformed to normalize the error variance before analysis (Noe, 1985). Data were analyzed using the GLM procedure of SAS for Windows System Version 6.12 (SAS Institute, Cary, NC). Means were separated using $\mathrm{F}$ test and Duncan's multiple range test.

\section{Results and Discussion}

Blackville bell pepper-cucumber studies. The soil density of $M$. incognita $\mathbf{J} 2$ was about 21

Table 1. Gall index, numbers of Meloidogyne incognita eggs per g fresh root and second stage juveniles (J2s) per $100 \mathrm{~cm}^{3}$ soil, total fruit yield, and total fruit numbers of 'Charleston Belle' and 'Keystone Resistant Giant' bell peppers.

\begin{tabular}{|c|c|c|c|c|c|}
\hline $\begin{array}{l}\text { Pepper } \\
\text { cultivar }^{z}\end{array}$ & $\begin{array}{c}\text { Gall } \\
\text { index }\end{array}$ & $\begin{array}{c}\text { Eggs/g } \\
\text { fresh root }^{\mathrm{x}}\end{array}$ & $\begin{array}{c}\mathrm{J} 2 \mathrm{~s} / \\
100 \mathrm{~cm}^{3}\end{array}$ & $\begin{array}{c}\text { Yield } \\
(\mathrm{kg} / \text { plot })^{\mathrm{w}}\end{array}$ & $\begin{array}{c}\text { No. } \\
\text { fruit/plot }^{\mathrm{w}}\end{array}$ \\
\hline \multicolumn{6}{|l|}{ Blackville, S.C. } \\
\hline Charleston Belle & $1.0^{* * * * * *}$ & $8^{* * * * *}$ & $1^{* * * * *}$ & 18.7 & $70^{* * * * * *}$ \\
\hline Keystone Resistant Giant & 4.3 & 1,868 & 168 & 16.9 & 57 \\
\hline \multicolumn{6}{|l|}{ Tifton, Ga. } \\
\hline Charleston Belle & $1.3^{* * * *}$ & $1,179^{* * *}$ & $16^{* * * * *}$ & $46.2^{* * *}$ & $132^{* *}$ \\
\hline Keystone Resistant Giant & 2.0 & 5,583 & 184 & 27.0 & 84 \\
\hline \multicolumn{6}{|l|}{ Combined analysis of both tests } \\
\hline Charleston Belle & $1.2^{* * * * *}$ & $98^{* * * *}$ & $5^{* * * * *}$ & $32.5^{* * *}$ & $101^{* * * *}$ \\
\hline Keystone Resistant Giant & 3.1 & 3,230 & 176 & 21.9 & 71 \\
\hline
\end{tabular}

z'Charleston Belle' resistant and 'Keystone Resistant Giant' susceptible to $M$. incognita.

${ }^{\mathrm{y}}$ Gall index: $1=0 \%$ to $3 \%$ root system galled, $2=4 \%$ to $25 \%, 3=26 \%$ to $50 \%, 4=51 \%$ to $79 \%$, and $5=$ $80 \%$ to $100 \%$ root system galled.

${ }^{\mathrm{x}}$ Data were $\log _{10}(\mathrm{x}+1)$ transformed before analysis. Back transformed data are shown. wTenty-five plants per plot.

${ }^{* * * * * * * * * * *}$ Significant at $P \leq 0.01,0.001$, or 0.0001 , respectively, according to $\mathrm{F}$ tests.

Table 2. Gall index, numbers of Meloidogyne incognita eggs per gram fresh root, fresh shoot weight, total fruit yield, and total fruit numbers of 'Stonewall' cucumber double-cropped after 'Charleston Belle' and 'Keystone Resistant Giant' bell peppers with metam sodium application at termination of the bell pepper crop.

\begin{tabular}{|c|c|c|c|c|c|c|}
\hline $\begin{array}{l}\text { Previous } \\
\text { pepper } \\
\text { cultivar }^{\mathrm{z}}\end{array}$ & $\begin{array}{c}\text { Metam } \\
\text { sodium }^{y}\end{array}$ & $\begin{array}{l}\text { Gall } \\
\text { index }\end{array}$ & $\begin{array}{c}\text { Eggs/g } \\
\text { fresh } \text { root }^{\mathrm{w}}\end{array}$ & $\begin{array}{c}\text { Fresh } \\
\text { shoot wt } \\
(\mathrm{g} / \text { plot) }\end{array}$ & $\begin{array}{c}\text { Yield } \\
(\mathrm{kg} / \mathrm{plot})^{\mathrm{u}}\end{array}$ & $\begin{array}{l}\text { No. } \\
\text { fruit/plot }{ }^{\mathrm{u}}\end{array}$ \\
\hline \multicolumn{7}{|l|}{ Blackville, S.C. } \\
\hline \multirow[t]{2}{*}{ Charleston Belle } & 0 & $1.3 \mathrm{a}^{\mathrm{t}}$ & $337 \mathrm{~b}$ & $481 \mathrm{~b}$ & $4.8 \mathrm{a}$ & $9 \mathrm{ab}$ \\
\hline & + & $1.2 \mathrm{a}$ & $41 \mathrm{a}$ & $512 \mathrm{~b}$ & $5.5 \mathrm{a}$ & $11 \mathrm{~b}$ \\
\hline \multirow[t]{2}{*}{ Keystone Resistant Giant } & 0 & $4.6 \mathrm{c}$ & $68,140 \mathrm{c}$ & $137 \mathrm{a}$ & $2.0 \mathrm{a}$ & $3 a$ \\
\hline & + & $3.4 \mathrm{~b}$ & $23,217 \mathrm{c}$ & $453 \mathrm{~b}$ & $7.7 \mathrm{a}$ & $12 \mathrm{~b}$ \\
\hline \multicolumn{7}{|l|}{ Tifton, Ga. } \\
\hline \multirow{2}{*}{ Charleston Belle } & 0 & $4.7 \mathrm{ab}$ & $9,741 \mathrm{a}$ & --- & $80.2 \mathrm{a}$ & $89 \mathrm{a}$ \\
\hline & + & $4.3 \mathrm{a}$ & $11,397 \mathrm{a}$ & --- & $181.1 \mathrm{~b}$ & $182 \mathrm{~b}$ \\
\hline \multirow[t]{2}{*}{ Keystone Resistant Giant } & 0 & $4.9 \mathrm{~b}$ & $9,656 \mathrm{a}$ & --- & $58.4 \mathrm{a}$ & $63 \mathrm{a}$ \\
\hline & + & $4.3 \mathrm{a}$ & $12,337 \mathrm{a}$ & --- & $176.7 \mathrm{~b}$ & $183 \mathrm{~b}$ \\
\hline \multicolumn{7}{|l|}{ Combined analysis of both tests } \\
\hline \multirow[t]{2}{*}{ Charleston Belle } & 0 & $3.0 \mathrm{~b}$ & $2,000 \mathrm{~b}$ & --- & $42.6 \mathrm{a}$ & $49 \mathrm{ab}$ \\
\hline & + & $2.7 \mathrm{a}$ & $460 \mathrm{a}$ & --- & $93.3 \mathrm{~b}$ & $96 \mathrm{bc}$ \\
\hline \multirow[t]{2}{*}{ Keystone Resistant Giant } & 0 & $4.7 \mathrm{~d}$ & $29,492 \mathrm{c}$ & --- & $30.2 \mathrm{a}$ & $33 \mathrm{a}$ \\
\hline & + & $3.9 \mathrm{c}$ & $16,611 \mathrm{c}$ & --- & $92.2 \mathrm{~b}$ & $97 \mathrm{c}$ \\
\hline
\end{tabular}

${ }^{\mathrm{z}}$ Charleston Belle resistant and Keystone Resistant Giant susceptible to $M$. incognita.

y Treatment with metam sodium at $467 \mathrm{~L} \cdot \mathrm{ha}^{-1}$ at termination of pepper study.

${ }^{\mathrm{x}}$ Gall index: $1=0 \%$ to $3 \%$ root system galled, $2=4 \%$ to $25 \%, 3=26 \%$ to $50 \%, 4=51 \%$ to $79 \%$, and $5=$ $80 \%$ to $100 \%$ root system galled.

wData were $\log _{10}(\mathrm{x}+1)$ transformed before analysis. Back transformed data are shown.

${ }^{v}$ Five plants per plot.

uTwenty-five plants per plot.

'Values in a column followed by the same letter are not significantly different according to Duncan's multiple range test $(P \leq 0.05)$. 
$\leq 0.05)$ M. incognita eggs per gram fresh root than plants following the susceptible 'Keystone Resistant Giant'(Table 2). Root galling of cucumber plants grown following 'Keystone Resistant Giant' was reduced in plots that had been treated with metam sodium compared with untreated plots; however, differences were not detected between root gall indices of cucumber plants grown after 'Charleston Belle' in the untreated and metam sodium treated plots. Numbers of eggs per gram fresh root were less $(P \leq 0.05)$ in cucumber grown after 'Charleston Belle' than in that grown after 'Keystone Resistant Giant' in both metam sodium treated and untreated plots. Although the numbers of eggs per gram fresh root in cucumber grown after 'Charleston Belle' were less in metam sodium treated plots than in the untreated plots (41 and 337 eggs/g fresh root, respectively), these relatively small differences are probably not biologically significant. Cucumber plants grown following 'Keystone Resistant Giant' in metam sodium treated plots had lower root gall indices $(P \geq 0.05)$ than those following 'Keystone Resistant Giant' in untreated plots, but differences were not detected in numbers of eggs per gram fresh root between the metam sodium treatment and untreated control. Fresh shoot weights of cucumber plants grown following 'Keystone Resistant Giant' in plots not treated with metam sodium were $70 \%$ to $73 \%$ less $(P \leq 0.05)$ than those from any other treatment combinations. There was a similar trend of reduced fruit yield of cucumber grown after 'Keystone Resistant Giant' in untreated control plots compared to the other treatment combinations, but significant differences in fruit yield were not detected among treatments.

Tifton bell pepper-cucumber studies. The soil density of $M$. incognita $\mathrm{J} 2$ was about 13 per $100 \mathrm{~cm}^{3}$ soil at planting. 'Charleston Belle' had a root gall severity index of 1.3 and 1,179 M. incognita eggs per gram fresh root (Table 1). 'Keystone Resistant Giant' had a root gall severity index of 2.0 and 5,583 M. incognita eggs/g fresh root. 'Charleston Belle' had 78.9\% fewer $(P \leq 0.001)$ eggs per gram fresh root than 'Keystone Resistant Giant'. Soil densities of $M$. incognita $\mathrm{J} 2$ were $91.3 \%$ lower $(P \leq$ $0.0001)$ in plots where 'Charleston Belle' had been planted than where 'Keystone Resistant Giant' had been planted. 'Charleston Belle' produced $42 \%(P \leq 0.01)$ heavier fruit yields and $37 \%$ greater $(P \leq 0.01)$ numbers of fruit than 'Keystone Resistant Giant'.

Cucumber plants grown following 'Keystone Resistant Giant' in metam sodium treated plots had somewhat less severe root galling $(P \leq 0.05)$ than cucumber following 'Key- stone Resistant Giant' in untreated plots (gall indices $=4.3$ and 4.9 , respectively) (Table 2 ). Differences were not observed among any of the treatment combinations for numbers of $M$. incognita eggs per gram fresh root of cucumber. Cucumber yields were $56 \%$ and $67 \%$ heavier $(P$ $\leq 0.05$ ) in metam sodium treated plots following 'Charleston Belle' and 'Keystone Resistant Giant', respectively, than in untreated control plots for the same cultivars. Plants produced $58 \%$ more fruit (averaged over cultivars, $P$ $\leq 0.05$ ) in metam sodium treated plots than cucumber yields in untreated plots.

Results of the combined analysis over locations were included (Tables 1 and 2) because there were interactions for several variables. For example, 'Keystone Resistant Giant' exhibited a susceptible reaction in the Blackville study for both the gall index (4.3) and numbers of eggs per gram fresh root $(1,868)$. However, 'Keystone Resistant Giant' would be classified as resistant based on the root gall index (2.0) in the Tifton study because a susceptible rating is typically defined as $\geq 3.0$ on a 1 to 5 rating scale. In contrast, reproduction of M. incognita on 'Keystone Resistant Giant' was high $(5,583$ eggs/g fresh root) in the Tifton study. In addition, fruit yields of 'Charleston Belle' were significantly heavier than its susceptible near-isogenic recurrent parent 'Keystone Resistant Giant'. Thus, it appears that 'Keystone Resistant Giant' was susceptible in the Tifton study.

In the combined analysis over locations, cucumber fruit yields were greatest $(P \leq$ $0.05)$ plots treated with metam sodium following either 'Charleston Belle' or 'Keystone Resistant Giant'. Thus, treatment with metam sodium provided a significant yield benefit for cucumber regardless of which pepper cultivar was grown as the first crop. Although not statistically significant, yields of cucumber grown in untreated plots following 'Charleston Belle' were $29 \%$ greater than yields of cucumber in untreated plots following 'Keystone Resistant Giant'. Cucumber grown in plots following 'Charleston Belle' and treated with metam sodium had the lowest $(P \leq 0.05)$ root gall severity and lowest $(P \leq 0.05)$ numbers of $M$. incognita in the roots. In contrast, root gall severity and nematode reproduction were highest $(P \leq 0.05)$ for cucumber grown in plots following 'Keystone Resistant Giant' without metam sodium treatment. Residual nematode pressure and damage to a subsequently planted susceptible crop would likely be reduced in the resistant pepper-cucumber rotation compared to the susceptible pepper-cucumber rotation. We concluded that application of metam sodium through the drip irrigation system following a spring crop of root-knot nematode resistant bell pepper such as 'Charleston Belle' should reduce severity of root galling and reproduction of $M$. incognita as well as increase fruit yield of fall-cropped cucumber.

\section{Literature Cited}

Colyer, P.D., T.L. Kirkpatrick, P.R. Vernon, J.D. Barham, and R.J. Bateman. 1998. Reducing Meloidogyne incognita injury to cucumber in a tomato-cucumber double-cropping system. J. Nematol. 30:226-231.

Fery, R.L., P.D. Dukes, Sr., and J.A. Thies. 1998. 'Carolina Wonder' and 'Charleston Belle': Southern root-knot nematode resistant bell peppers. HortScience 33:900-902.

Hanna, H. 2000. Double-cropping muskmelons with nematode-resistant tomatoes increases yield, but mulch color has no effect. HortScience 35:1213-1214.

Hanna, H.Y., P.D. Colyer, T.L. Kirkpatrick, D.J. Romaine, and P.R. Vernon. 1994. Feasibility of improving cucumber yield without chemical control in soils susceptible to nematode build-up. HortScience 29:1136-1138.

Hussey, R.S. and K.R. Barker. 1973. A comparison of methods of collecting inocula of Meloidogyne spp., including a new technique. Plant Dis. Rpt. 57:1025-1028.

Jenkins, W.R. 1964. A rapid centrifugal-flotation technique for separating nematodes from soil. Plant Dis. Rpt. 48:692.

Noe, J.P. 1985. Analysis and interpretation of data from nematological experiments, p. 187-196. In: K.R. Barker, C.C. Carter, and J.N. Sasser (eds.). An advanced treatise on Meloidogyne. vol. 2. Methodology. N.C. State Univ. Graphics, Raleigh.

North Carolina Vegetable Growers Association. 2004. Vegetable crop guidelines for the Southeastern U.S., 2004-2005. In: D.C. Sanders (ed.). N.C. Veg. Growers Assn.

Thies, J.A., R.F. Davis, J.D. Mueller, R.L. Fery, D.B. Langston, and G. Miller. 2004. Double-cropping cucumbers and squash after resistant bell pepper for root-knot nematode management. Plant Dis. 88:589-593

Thies, J.A., J.D. Mueller, and R.L. Fery. 1998. Use of a resistant pepper as a rotational crop to manage southern root-knot nematode. HortScience 33:716-718

U.S. Department of Agriculture. 1998. Vegetable: Acreage, production and value. Fla. Agr. Stat. Serv. Orlando. 29 Jan. 1998. http://www.nass. usda.gov.

U.S. Environmental Protection Agency. 2000. Protection of stratospheric ozone: Incorporation of Clean Air Act amendments for reductions in Class I, Group VI controlled substances. Fed. Reg. 65 (No. 229):70795-70804.

Webster, T.M., A.S. Csinos, A.W. Johnson, C.C. Dowler, D.R. Sumner, and R.L. Fery. 2001. Methyl bromide alternatives in a bell peppersquash rotation. Crop Protection 20:605-614. 